\title{
The Current Situation and Prospects of China's Higher Education of English in General Education
}

\author{
Luoxia Wang \\ Hebei Institute of Communications \\ Shijiazhuang,Hebei,China
}

\author{
Zongju Li \\ Hebei Institute of Communications \\ Shijiazhuang,Hebei,China
}

\begin{abstract}
General education is an important part of education; it aims to cultivate students to be person and citizens of high responsibility. It is the product of combination between liberal education and American education. China's Higher Education of English is still facing many challenges. Liberal education provided enlightenment for the development of China's Higher Education of English. We should introduce a critical perspective when teaching English. As regard to the curriculum building, we should set up core curriculum containing literary classical and outstanding culture. English Teaching ought to create constructivist classroom which designed as student-centered. What remains an important task for us to solve is to return to the humanist tradition of English education.
\end{abstract}

Keywords- general education; liberal education; English

\section{INTRODUCTION}

Modern Liberal Studies is called "general education" by some scholars in China. It is an educational ideology and model as the result of professionalism education and vocational education in higher education and vocational education. It is originated from ancient Greece when Aristotle advocated liberal education. Liberal education takes human as its fundamental part, to pursue spiritual freedom and liberation. In the course of development of the modern university, due to the development of the industrial revolution and the rise of scientism, non-utilitarian liberal education has been gradually replaced by utilitarian professional education, and then developed into a professionalism as well as instrumentalism which made man to be a vassal of knowledge. During the critique for professional education, the Liberal idea first came into being in 1828 at Yale University in which the most popular American professional doctrine when a report first use the words "general education". In 1930, Hut chins advocated the movement of studying classics when elected as the president of Chicago, which opened the modern general education curriculum. In 1945, the report "a free society in general education," from Harvard University first presented the modern sense of education. In 1979, the "report on the Harvard School of Arts and common basic courses" redefined undergraduate education goals, which made general education become the main form in Harvard's teaching reform. Thus, Aristotle's liberal education in the United States evolved into the modern sense of general education, and had a significant impact on the development of higher education in many countries and regions. It is about a decade earlier for Taiwan and Hong Kong introduced the concept of general education than the mainland did. The research and practice of general education in mainland of China is still in its infancy stage. This shows the importance of researching and promoting the general education. This paper aims to research, analyze and rational introspect the current development of China's general education fro $\mathrm{m} t$ wo dimensions of theory and practice, in order to better grasp the law and practice of general education and better promote our general education development.

\section{THE ISSUE OF LIBERAL EDUCATION AND ITS DEFINITION}

In China, education reform, especially higher education reform has been a hot topic. All he previous leaders in educational administration have trying to change the unfavorable educational situation; however, it turned out to be little success. With countless variety of educational philosophy exist, then what kind of ideas are suitable for the reform of China's educational institutions? With this is sue in mind, we focus on the "general education" introduced by Europe and other countries, and the discussion of liberal studies' carrying out in China in policy level, in order to contribute to reasonable decisions. Any kind of decisionmaking has its risks, but what we have to do is to minimize the risk of decision-makers. Optimizing decisions and risk aversion have become the consensus of modern decision theory, the administrative decision-making as well. The research about education policy is based on China's current situation and forms of education, so as to make the introduction and implementation of education policy procedural, theoretical and rational, to avoid potential serious risk so that achieve optimu m decisions, save social resources, reduce social costs of reform, promote social development, especially education.

\section{THE CURRENT SITUATION OF GENERAL EDUCATION AND ITS TRENDS OF POLICY IN CHINA}

In recent years, Liberal education experienced rapid development in the field of higher education, we are very 
pleased to see many famous universities are more or less concerned about the general education and put it into practice, such as the elective system in our school, students can choose art courses besides public courses and specialized courses. Another example, the original Yuanpei experimental classes from Peking University makes efforts to implement the policy of "Strengthening the foundation, dilute professional, individualized, triage training". It take advantage of its full range of disciplines and good teaching resources, practicing its educational ideology of successfully combine the general education of junior in undergraduate with wide caliber and professional education in senior education. It focuses on comprehensive training of foundation, ability and quality, and deliver backup students of high-quality and innovative to graduate education, as well as provide graduates adapt to the economic construction and social development. Such cases are not uncommon in our country but general education in China's universities is still hazy, on a low stage, and not comprehensive. If general education is communis $\mathrm{m}$, it seems that our general education is on a lower stage of socialism. It means that we can only meet the food and clothing of the people, yet well-off. We are extremely embarrassed. This is a difficult task the era gave us, education need to be developed, the society need to make progress, and the general education may be a better approach for development.

\section{THE IMPACT THAT GENERAL EDUCATION HAS ON EDUCATION POLICY}

The trends of general education in modern society is more systematic, comprehensive, and international, it contains many elements of science and humanities. This standard is bound to put forward higher requirements to the quality of teachers and also teaching ideas, which requires both in policy formulation level and decision-making level, we should base on the overall situation and focus on the future, and establish a strategic development objectives in the world competition, and make it worked well. Reform is bound to lose something, but if we do not reform, the loss will be greater and more devastating. The pattern of international competition is emerged in the process of development, when developed slowly or become stagnant, we are only to be beaten in a passive state, in that case, the problem of education is not a simple question, and however, it has risen to the height that relevant to the development of the nation. And only treat it on this level can we make better choices from various theories, to implement and practice.

\section{THE PREDICAMENT THAT CHINESE GENERAL EDUCATION IN UNIVERSITY FACING FOR DEVELOPMENT}

According to the analysis above, we can find that our general education has made tremendous progress. The personnel training and education have gradually shifted from "system controller" to "educate people". The Liberal ideas are being transformed into a variety of modes of practice. However, China's general education is still on its initial stage. Whether regard to ontological research or epistemology research or practice theory research or practice, there are many problems and shortcomings we cannot ignore. Further reflection, deepening research and strengthened practice is the responsibility and obligation of higher education workers. Facing such a compelling and ambiguous concept, the ontology study of general education is particularly important, but the domestic scholars reach no consensus understanding of the concept of "general education". By its nature, general education is an integral part of higher education, the nonprofessional education that all college students should receive. General education aims to develop the citizens who take active participation in social life, developing in all round way, and with high sense of social responsibility. In terms of content, it is an education of broad, non-professional, nonutilitarian basic knowledge, as well as skills and attitudes. Domestic researchers mostly position it as a part of higher education, as a supplemental part of professional education. The combination of professional education and general education constitutes a college education.

\section{A. Problems of General Education}

General education attracts growing concern from educators. The college English teaching, with its own characteristics, it is of higher necessity to promote general education. Judging from the general education at this stage, we must first understand the meaning of general education, changing traditional concepts of education, making a deep understanding of the connotation of general education. With the popularization of higher education, general education should train students to broaden their knowledge in human spirit, on the basis of a broad knowledge. The idea of training talents of broad background of knowledge and of overall quality should gradually accepted by the public. In addition, the university's general education English classes need to be implemented through general education courses. Setting up general education courses is the main way to complete general education goals, to work hard in the curriculum aspect, rationalize the relationship between education and general education in English, so that the two are able to achieve a common training goal. For the teachers, the English teachers should not only good at speaking and writing, they themselves should also be of high moral characters, being erudite scholars.

\section{B. The Goal of English teaching is to develop students' ability to comprehensively apply English}

The goal of English teaching is to develop students' ability to use English, while enhancing their self-learning ability, improving their overall cultural quality to meet the needs of China's economic development and international exchanges. We find that both the outline and teaching require ments are related to the content of general education. According to the outline, the talents it cultivated are in line with the outline of general education which proposed by Western countries. In terms of teaching requirements, as advocated, is the educational model of "comprehensive knowledge and comprehensive quality," in other words, through teaching students the full range of knowledge to train them with comprehensive quality. At this stage, the purpose of college English teaching is to make knowledge of 
languages, foreign cultures and other subjects integrate with each other during teaching. To transform college English courses into a comprehensive, multidisciplinary curriculum which combines English language learning, skills training, and intercultural communication. No language is isolated; it is always deeply rooted in a national culture. Experts noted that English teaching has two functions: functionality as a tool and overall functionality. The function as a tool of English teaching has became a heated point because its value of practical use. It is widely believed that English is just a tool; in fact, the function of language teaching is more than that. Language is the carrier of culture, so when we teach our language to students, we pass them broad cultures of various countries at the same time. So they can enjoy the cultural transmission and have deeper knowledge when learning.

\section{The Advantages of Carry out General Education in English Teaching}

As a direct manifestation of knowledge like others, culture is also a language. It's an understanding activity, but also the performance of linguistic phenomena. Language teaching is not only to enable learners to master pronunciation, vocabulary and grammar of the language, but also to make them aware how the language-speaking countries use their language to reflect their values, worldviews and codes of conduct. We should understand their cultural society. The standard particularly emphas is on the importance of understanding the relevant information and knowledge of foreign languages through learning, and make sure that it should be linked with other disciplines in the process of learning a foreign language.

In recent years, some visional scholars in English learning industry have been actively explored the way of foreign language teaching. Profess or Wu Dimming once based on the characteristics of college English, clearly put forward the educational ideology which systematically put English language, foreign cultural and multidisciplinary knowledge together. To transform college English courses into a comprehensive, multidisciplinary curriculum which combines English language learning, skills training, intercultural communication, namely, the general education. The reas on for the application of general education in college English teaching is that education in college is not for specific purpose but for integrative purpose. The goal of English teaching is to develop students ' ability to use English, while enhancing their self-learning ability, improving their overall cultural quality to meet the needs of China's economic development and international exchanges.

VI. THE KEY POINT S OF CONST RUCTING THE CURRICULUM SYST EM OF GENERAL EDUCATION IN ENGLISH TEACHING

\section{A. Center on the particularity of College English Teaching to Construct General Education Curriculum, Chronological and Convenient}

However, the current implementation of general education still facing many problems, the most important problem is the lack of qualified teachers who understand the "General Education". It's more severe in single major school, especially in science and technology schools, engineering school. Thus, while constructing college English teaching courses in general education system, the faculty building is fundamental. Teachers should set good examples, such as fully understand the importance of general education, to strengthen their training and promote the overall quality of them, as well as actively improve their teaching methods. Meanwhile, the construction of teachers should respect and encourage individual lectures.

\section{B. Play the Initiative of Students is the Key to Construct General Education Curriculum System}

The leading role of students in English teaching process is indisputable, so teachers should fully mobilize the enthusiasm of the students, and actively guide students to change their understanding, shifting from passive learning to active learning. We should advocate students to read widely in English journals, magazines and learn a wealth of knowledge, including both natural science and social science. Meanwhile, there are rich resources on the Internet that students can choose from.

\section{CONCLUSION}

General education has become an integral part of higher education in China. It's not only a new educational philosophy of constructing university, but also a sound curriculum system being constructed. The construction of general education in college English teaching in science and engineering university is in line with the trend of college English teaching reform, and in compliance with the characteristics of science and engineering univers ities as well as their students. It's conducive to cultivate students who are not only having a wealth of knowledge of English, but also with comprehensive quality such as high capacity and training.

\section{REFERENCES}

[1] Ma Yumpie. Higher Education in China English Liberal Perspective [J]. Heilongjiang College of Education ,2013,09:166-168.

[2] Liqing Chen. General Education: Higher Education Development realistic choice [J] Zhouk ou Teachers College ,2006,01:132-135.

[3] Wang baohuan. Liberal: new talent and practice to explore the era of mass higher education [J] NAEA Journal ,2007,05:61-65.

[4] Yue Linlin, Cheng Yuesen. General education courses in medical colleges design patterns [J]. Education Review ,2014,01:114-116.

[5] Cui Lili. Higher general education curriculum system construction of cross-cultural study [J]. Shenyang Agricultural University (Social Science Edition) ,2013,06:725-729.

[6] Deng Xin, Duxue Juan. English teaching Liberal Perspective [J]. CULTURE ,2013,30:179-181.

[7] Li Yuying. Exploration Liberal Perspective college English teaching reform in China [J]. Young writers, 2014,08:228. 